\section{IJßER}

ISSN: 2149-5939
International Journal of Social Sciences and Education Research

Online, http://dergipark.gov.tr/ijsser

Volume: 3(1), 2017

\title{
Time, video, and the end of cinema
}

\section{Bülent Eken ${ }^{1}$}

Received Date: 01 / 09 / 2016

Accepted Date: 15 / 12 / 2016

\begin{abstract}
The discussions of the end of cinema tend to privilege the emergence of digital technology as a turning point. In this paper, I argue for the centrality of the category of the "viewer", which as a concept makes visible the essence of the medium of cinema. This essence is the preservation of time in which the viewer has a stake in relation to his or her memory. This then shows the limits for a possible discussion of the end of cinema. If there is a certain type of film that leaves no room for the spectator, then this could mark one sense of an end. I take the mainstream entertainment cinema that is based in staging a "spectacle" as an example. The temporality of cinema is also surpassed in the direction of video, which does not preserve time by constructing image-objects but participates in a time-matter in which all is already an image.
\end{abstract}

Keywords: time, audience, spectacle, video, digital culture

\section{Time, video, and the end of cinema}

It is indispensable to have a concept of "audience" for forming a true idea about the essence of the medium of cinema. However, this is not the same problem as the obviously essential place of the audience or the viewer for the institution of cinema, since it is not obvious at all how, according to which function, (the concept of) the viewer defines the medium of cinema or makes it difficult to define this medium when it is absent or misconstrued. In fact, one can even see that it is possible to talk about a film or a certain type of film that is "without an audience" in the sense that it vacates the function related to the concept of the audience that is constitutive of the medium of cinema.

My first example for delineating this idea comes from Andrei Tarkovsky's reflections, while discussing the specificity of the film image, on the audience in cinema. What Tarkovsky has to say about the film audience provides an excellent example for the essential link the medium of cinema has with the viewer. Tarkovsky, who is constantly faced with the accusation that his films are incomprehensible for the viewer, voices his protest as follows:

I have always been infuriated by the formula, 'people won't understand'. What does it mean? Who can take it upon themselves to express the 'people's opinion', making declarations on their own behalf as if quoting the majority of the population? Who can know what people will or won't understand? What they need or what they want? Has anyone ever conducted a survey or made the slightest conscientious effort to discover the people's true interest, their ways of thinking, expectations, hopes —or, indeed, disappointments? I am a part of my people: I have lived with my fellow-citizens, been through the same bit of history as anyone else of my age, observed and thought about the same happenings and processes, and even now, in the West, I remain a son of my country, I am a fragment of it, a particle, and I hope that I express ideas that stem from deep within our cultural and historical traditions. (Tarkovsky, 2000, pp.172-73)

\footnotetext{
${ }^{1}$ Kadir Has University, İstanbul, TURKEY, bteken @ gmail.com
} 
Eken, B. (2017). Time, video, and the end of cinema. International Journal of Social Sciences and Education Research, 3(1), 101-105.

In this same work, Tarkovsky also reproduces some letters from his viewers which he believes ratifies the truth of his understanding of cinema. A viewer writes the following, for instance: "Thank you for Mirror. My childhood was like that. . . Only how did you know about it? ... You know, in that dark cinema, looking at a piece of canvas lit up by your talent, I felt for the first time in my life that I was not alone." (Tarkovsky, p.10) Here is another: "I went to a discussion of the film [i.e. Mirror]. 'Physicists' and 'Lyricists' were unanimous: the film is compassionate, honest, relevant - all thanks to the author. And everyone who spoke said, 'The film is about me."' (Tarkovsky, p.11). And yet a different one: "I've seen your film four times in the last week. ... Everything that torments me, everything I don't have and that I long for, that makes me indignant, or sick, or suffocates me, everything that gives me a feeling of light and warmth, and by which I live, and everything that destroys me - it's all there in your film, I see it as if in a mirror. For the first time ever a film has become something real for me, and this is why I go to see it, I want to get right inside it, so that I can really be alive." (Tarkovsky, p. 12)

What is important about these quotations is not simply their perfect echo of Tarkovsky's implicit assertion that it is a total historical existence that constitutes the character of a people and, since nothing could be added or excluded to it by will, it is the truthfulness with which a film confronts this existence that brings it home to the people/audience. In this context, both the title of Tarkovsky's film and the metaphors of self-recognition found in the audience responses resonates with a more general metaphor of the movie screen as a mirror, which I will explore in my next example of psychoanalytic film criticism, that reconfirms the essential link between the medium of cinema and the audience. More important in these viewer reports is the clue they provide for the question of what cinema is or does so that it results in these experiences in the viewers. What must cinema be so that a viewer -independent of what transpires on the screen with the story, characters, and so on - can literally find his or her "childhood" in what he or she is watching? One must add that the authors of these letters to Tarkovsky are ordinary people who are workers, teachers, housewives, and so on. Exactly with what do these ordinary people enter into a relation in cinema?

Tarkovsky provides a very clear response to this question in discussing the nature of the film image. The distinctive thing about cinema is that it records the passage of time. "One cannot conceive of a cinematic work with no sense of time passing through the shot," Tarkovsky writes, "but one can easily imagine a film with no actors, music, décor or even editing." (p. 113). And to the question of how does this time, which is preserved in the shot, make itself felt in it, he gives a response that demonstrates why there is mutual implication between the viewer experience and the essence of the medium of cinema. The time preserved by the film becomes tangible when one feels, beyond what is depicted on the screen, the existence of something more significant or truthful; when one realizes that what one sees in the frame "is not limited to its visual depiction, but is a pointer to something stretching out beyond the frame and to infinity; a pointer to life." (Tarkovsky, p. 117-18). If time is within the shot, is recorded and preserved by the shot, this means that the shot itself falls within time. In turn, this means that time flows through the shot and beyond the edges of the frame. Finally, this is precisely what enables the viewer to participate in the film with his or her personal experience and memory. Personal experiences of the viewer (memories, dreams, desires, wishes, etc) are also fragments of time. For this reason, what happens in cinema is nothing less than establishing a relation with time within time. Thus, Tarkovsky is extremely sincere when he argued that there 
Eken, B. (2017). Time, video, and the end of cinema. International Journal of Social Sciences and

Education Research, 3(1), 101-105.

can be such thing as a film that won't be understood by the people. Since time is lived and experienced before being understood (whatever that might mean), to try to put limits on what can be experienced by recourse to arbitrary criteria of intelligibility is meaningless - or worse, it points to an insidious authoritarian regime.

One can conclude here that the mutually implicating necessary link between cinema and the audience is only established within the problematic of time. Conversely, a film that does not require its viewer to establish a temporal relation with itself, that does not care about the personal experience of the viewer refers to a cinema that is "without an audience." Can there exist such a cinema? I will come back to this question, but before doing so one can at least make a related observation on the fate of "national cinema".

What made it possible to see cinema as a tool for constructing and acting within a national and collective project of memory, arguably one of the main motivations behind the maturation of a period of national cinema worldwide, was its profound relation with the experience of the viewer. The primal scene of cinema is, after all, the gathering of strangers in a dark room around a common project of history and memory. And the devaluation of these projects, together with the crisis of the nation-state, also tells something about the decline of the institution of cinema that is essentially based on a specific synthesis of time. The emphasis both Tarkovsky and his viewers place on a common history and temporality is illuminating in this respect.

The psychoanalytic film criticism, which dominated the seventies, provides another angle on the question of the collective temporality of cinema that the spectator makes visible. Psychoanalysis introduces a new metaphor for the cinema screen, which now becomes a "mirror", and a new problematic for the analysis of films, i.e. "desire". (Andrew, 1984, p. 134). For the realists, the screen was a "window" opening onto reality; whereas for the formalists it was a "frame," which suggested that the relation to the real has to be achieved through radical formal work. The "mirror," however, changes the focus entirely: what becomes central now is the mechanism of "identification" which puts the "desire" of the spectator in a relation with phantasy, wish fulfillment, and ideological investment of collective beliefs. In the psychoanalytic perspective, too, the viewer assumes a constitutive role for cinema. For example, in the classical narrative cinema, psychoanalysis discovers the necessity of making a distinction between the narrative space and the space of the mise-en-scene. Tools or conventions like the 180degree rule or the organization of the actors' gaze show that in the classical narrative cinema the narrative space is organized around an ideal spectator who occupies the center, reanimates the mirror identifications of the spectator in terms of, for instance, the social gender norms. The emergence, from within the psychoanalytic criticism, of a proposal for an alternative cinema practice that deliberately does violence to the norms and conventions in cinema that sustain collective ideological structures must be understood in this context: the spectator is interested in cinema because it is the site of collective unconscious desire.

Now, one sense of the end of cinema might be sought in the gradual disappearance of the common historical temporal horizon that the cinematic recording of the passage of time made possible. And this development has nothing to do with the emergence of digital technologies or the ubiquitous availability of video technology in itself, although it might have to do with the temporal and aesthetic regime that is organized by the use of such technologies. I asked above whether a cinema without an audience and, therefore, one that does not record the passing of time really exists. Although it sounds counterintuitive to search for something like this, 
Eken, B. (2017). Time, video, and the end of cinema. International Journal of Social Sciences and Education Research, 3(1), 101-105.

many examples of the globally dominant mainstream entertainment cinema, whose hallmark is the creation and sustaining of "spectacle", seem to offer themselves as perfect candidates. For example, in Casino Royal, one of the latest in the James Bond film series, we find an eight minutes long chase scene with no dialogue. This scene contains all the elements that Andrew Darley (2000) attributes to the works that are characteristic of what he calls the "visual digital culture". It is a "simulation" since it invests in the realist, character driven narrative of liveaction cinema, whereas the details and the sequence of the action is far from being realistic, while this does not at all become a problem for the viewer. The reason why it is not felt as a problem is found in the fact that the viewer consumes the film as a "spectacle," which is not driven by any anxiety about the passage of time but the intensity of immersion in the moment. The spectacle fascinates not with the content of the image, what it is about, but with what the image is, precisely a fascinating surface play. Finally, this spectacle created by simulation is sustained with the help of "hybrid" images that are "hyperreal". The images in this chase sequence are hybrid - and they are neither pure object-images nor are they created with such an anxiety - in the sense that their fascination partly owes to the obscurity of their origin ("how do they shoot this?) and also that they are repetitions of images that have their origin in different media such as a computer game or a comic book. Lastly, these are "hyperreal" images in that they manage to remain realistic in those conditions that make realism impossible, when, say, there is no fire to be shot by a camera but a simulation created by a computer program instead.

It is impossible for the viewer to encounter something about his or her "childhood" here or to be attracted to these images on the basis of his or her experiences or memories. And there is a good reason for this, since the images of films like this do not have a relation with something that goes beyond the frame; rather, instead of being related to something "outside" they refer to other images that circulate in the spectacular atmosphere, from comic books to video games, from video games to movies and back. Since the images do not have an outside, there is also no room for the viewer in this spectacle who used to enjoy in cinema a relation with such an outside by means of his or her personal experience. The spectacle goes on and on without the slightest need for any viewer.

Niessen (2011) has persuasively argued that discussions about the end of cinema based on the analysis of the "indexical" nature of the film image against the background of the analog - digital distinction reaches a dead-end, because indexicality illuminates the image-object relationship in analog or digital production but does not specify anything about the relation between the viewer and the image, whether analog or digital. He thus dismisses the current meanings of the uses of the expression the "death of cinema". However, I just have registered a sense of the end of cinema, under the conditions of the spectacle, taking into account precisely the experience of the viewer: the end of the experience of time within time. I would like, finally, to register one last sense of the end of cinema or rather its overcoming in the case of video.

Writing about what "lies at the heart of the medium" of cinema Andrew (2009) is lead to a comparison of cinema and television in terms of their difference:

Cinema's voltage depends on delay and slippage, what I dub the décalage at the heart of the medium and of each film between "here and there" as well as "now and then." This French term connotes discrepancy in space and deferral or jump in time. At the most primary level, the film image leaps 
Eken, B. (2017). Time, video, and the end of cinema. International Journal of Social Sciences and Education Research, 3(1), 101-105.

from present to past, since what is edited and shown was filmed at least days, weeks, or months earlier. This slight stutter in its articulation then repeats itself in the time and distance that separates filmmaker from spectator, and spectators from each other when they see the same film on separate occasions. The gap in each of these relations constitutes cinema's difference from television. Films display traces of what is past and inaccessible, whereas the television feels (and often is) present (Andrew, p.60-1).

Yet, television is not simply "present"; it is, when one considers its technological basis, the "live" broadcasting of an event (simultaneity) based on the transmission of electric signals. Moreover, just as television never was interested in constructing object-images, as in cinema, there is never a completed image on the television screen at any given moment. (Dienst, 1994) Video, based on the electronic technology of television, has at its disposal a different time or the "time-matter" itself. Maurizio Lazzarato (2008) writes that the video image "takes its movement from the oscillations of matter; it is this oscillation itself. . . The video image is a result of contraction or dilation of time-matter." (284). As we have seen with Tarkovsky, the temporality of cinema has a particular affinity with collective memories. With the video, on the other hand, the scope of memory becomes cosmic. It is as if with video it becomes possible for the first time to construct a foreign memory that would nonetheless be one's own. Since, qua electricity or oscillation of matter, one does not create the video image, since the image is always already there, "when making a video production, one intervenes, connects to the continual process of universal change that already existed before one ever intended to use it . . . This duration could be called 'real-time', a duration that is unknown to film" (Lazzarato, p. 286). The film image individualized the viewer who was part of a collective, but the video image minoritizes the already individualized viewer into a cosmic collective.

\section{References}

Andrew, D. (1984). Concepts in Film Theory Oxford: Oxford University Press

Andrew, D. (2009). Time Zones and Jetlag. In World Cinemas, Transnational Perspectives. London: Routledge.

Darley, A. (2000). Visual Digital Culture. London: Routledge

Dienst, R. (1994). Still Life in Real Time: Theory After Television. Durham: Duke University Press.

Lazarrato, M. (2008). Video, Flows, and Real Time. In Art and The Moving Image. London: Tate Publishing.

Niessen, N. (2011). Lives of Cinema: against its 'death'. Screen, 52-3, 307-326.

Tarkovsky, A. (2000). Sculpting In Time. Austin: University of Texas Press. 